\title{
Intracerebral schwannoma: A case report and literature review
}

\author{
YUFEI GAO ${ }^{1}$, ZHIGANG QIN $^{1}$, DONGYUAN LI ${ }^{1}$, WEIDONG YU ${ }^{1}$, LIBO SUN $^{1}$, \\ NAIJIE LIU ${ }^{1}$, CONGHAI ZHAO ${ }^{1}$, BUTIAN ZHANG ${ }^{2}$, YU HU $^{3}$, DAJU SUN $^{3}$ and XINGYI JIN ${ }^{1}$ \\ Departments of ${ }^{1}$ Neurosurgery, ${ }^{2}$ Radiology and ${ }^{3}$ Pathology, \\ The China-Japan Union Hospital of Jilin University, Changchun, Jilin 130033, P.R. China
}

Received March 9, 2017; Accepted September 28, 2017

DOI: $10.3892 / \mathrm{ol} .2018 .8949$

\begin{abstract}
Intracranial schwannoma accounts for between 5 and $8 \%$ of intracranial tumors, whereas intracerebral schwannoma, a rare disease, accounts for $<1 \%$ of intracranial schwannomas. In addition to the present case report, a total of 84 cases reported within China and elsewhere were reviewed and summarized, and the age of the tumor onset, the site of disease, imaging results, clinical presentation, pathological classification and prognosis were analyzed. The present case report described a 12-year-old female with an intracerebral schwannoma in the brainstem, who was followed-up for 5 years using magnetic resonance imaging after a surgical resection without recurrence, and clinical symptoms were reported to have completely resolved. The incidence of intracerebral schwannoma was low among cases, and the correct diagnosis was not able to be made preoperatively, and the majority of cases were diagnosed on the basis of postoperative pathology. The majority of cases analyzed were supratentorial, occurring at an age $\leq 40$ according to previous literature. In addition, 33\% of patients presented with subtentorial schwannoma, occurring at an age $>40$. The prognosis was classified as good (patient can live independently) for the majority of patients if surgery was able to completely resect the lesion.
\end{abstract}

\section{Introduction}

Intracranial schwannoma accounts for between 5 and $8 \%$ of intracranial tumors, whereas intracerebral schwannoma, a rare disease, accounts for $<1 \%$ of intracranial schwannomas (1). Intracerebral schwannoma cannot be clearly diagnosed with preoperative clinical manifestations and/or results generated

Correspondence to: Dr Xingyi Jin, Department of Neurosurgery, The China-Japan Union Hospital of Jilin University, 126 Xiantai Street, Changchun, Jilin 130033, P.R. China

E-mail: jin5756@163.com

Abbreviations: EMA, epithelial membrane antigen; GFAP, glial fibrillary acidic protein; MRI, magnetic resonance imaging

Key words: incidence of a disease, intracerebral schwannoma, site of disease, case report, literature review from imaging techniques. It is clearly diagnosed on the basis of postoperative pathology (1-4). However, no previous study, to the best of our knowledge has systematically summarized the disease characteristics, including the incidence of patients, the onset age, tumor location, clinical manifestation and prognosis. The present study not only had complied this case report, but also summarized the characteristics of intracerebral schwannoma, which will further deepen the knowledge and understanding presently available of this disease. In additional to the present case report, 84 cases reported within China and elsewhere were summarized, and the age of the tumor onset, site of disease, imaging results, clinical symptoms, pathological classification and prognosis were reviewed and analyzed. Characteristics of intracerebral schwannoma were summarized as follows: Incidence of intracerebral schwannoma was low among cases, the majority of cases had supratentorial tumors and the patients were of an age $\leq 40$, $<33 \%$ of tumors were subtentorial and onset was demonstrated in cases of an age $>40$; correct diagnosis was not typically achieved preoperatively and the majority of cases were definitively diagnosed on the basis of postoperative pathological analysis. Furthermore, for patients whose normal brain tissue was minimally affected by the tumor, if surgery was able to completely resect the lesion and the prognosis was good.

\section{Case report}

The present case report was carried out in accordance with the code of ethics outlined by the World Medical Association (The Declaration of Helsinki) for experiments involving humans. Informed consent was obtained for all experiments regarding human subjects.

In the present case report, written informed consent was obtained from the parents due to the age of the patient (12 years). The patient was admitted to the Department of Neurosurgery, The China Japan Union Hospital of Jilin University (Jilin, China). The female patient was of Han nationality and did not have a family history of this particular genetic disease. Symptoms upon presentation included dizziness (lasting for 1 year before examination), headache, nausea, vomiting and require assistance with walking. Physical examination demonstrated that binocular vision was normal, bilateral pupils were of the same size, eyes were sensitive to light reflection and eyeballs moved freely in all directions. Furthermore, facial sensation was normal, binocular horizontal nystagmus was 
present and the reflex of bilateral corneas was slow. Muscle tension of the four limbs was normal and the finger-nose test of the left side was positive with no pathological reflex detected. Preoperative magnetic resonance imaging (MRI) of the head demonstrated an abnormal cystic signal in the cerebellar vermis, and parenchyma parts presented nodular isointensity shadows above the cystic wall; additionally, there was no obstructive dilatation in bilateral lateral ventricles or the third ventricle. Preoperatively, the patient was diagnosed with glioma in the cerebellar vermis, and therefore a cerebellar hemisphere tumor resection from the median suboccipital approach was organized for the patient. As a brainstem parenchymal tumor was not considered, and there were no obvious hydrocephalus symptoms prior to the operation, no neurophysiological monitoring or ventricular drainage was performed. However, during surgery, the tumor was revealed to have originated from the brainstem parenchyma (Fig. 1). Further analysis of the preoperative MRI film confirmed results reported during surgery.

The origin of intracerebral schwannoma and intracranial schwannoma display differences in their pathogenic sites; however, in patient's MRIs no differences were detected. The fourth ventricle was deformed due to tumor oppression. The tumor surface consisted of a layer of parenchymal tissue of the brainstem; $10 \mathrm{ml}$ light yellow liquid was extracted by puncturing the cyst while the dorsal brainstem was collapsed. The left side of the cerebellar tonsils was stripped to locate the parenchymal tumor tissue above the cyst wall. The tumor tissue was revealed to be rich in blood supply, hard in texture and gray-red with calcification inside and a clear border, and the resected solid tumor was $1.5 \times 1.5 \times 1.5 \mathrm{~cm}$ in size. Notably, the cyst wall was excised completely and the patient did not develop transient post-surgery hydrocephalus. MRI of the head was reviewed 10 days after surgery and demonstrated that the tumor was completely resected and the brainstem was restored to its original position (Fig. 2). Results obtained from pathological analysis demonstrated that the patient had a schwannoma within the brainstem.

For immunohistochemistry (IHC), tissue sections were treated with $2 \% \mathrm{H}_{2} \mathrm{O}_{2}$ in methanol for $1 \mathrm{~h}$ at $120^{\circ} \mathrm{C}$ to inactivate endogenous peroxidase. The sections were washed twice with PBS and then incubated with blocking serum (MXB Biotechnologies, Fuzhou, China; http://www.maxim.com.cn/) for $1 \mathrm{~h}$. The sections were then incubated with cytokeratin 20 (cat. no. Ks20.8), carcinoembryonic antigen (cat. no. ZC23) and cell proliferation factor Ki67 (MIB-1) pre-diluted primary antibodies (all purchased from MXB Biotechnologies) for $1 \mathrm{~h}$ at $37^{\circ} \mathrm{C}$. Then sections were then washed with PBS and incubated with a biotinylated goat anti-rabbit secondary antibody (ready to use dilution; Kit-0014; MXB Biotechnologies) for $1 \mathrm{~h}$ at $37^{\circ} \mathrm{C}$. Sections were then treated with $\mathrm{ABC}$ solution (MXB Biotechnologies) for $1 \mathrm{~h}$ at $23^{\circ} \mathrm{C}$, washed with PBS, and incubated with DAB (MXB Biotechnologies) for $10 \mathrm{~min}$ at $23^{\circ} \mathrm{C}$. The IHC results were observed using a light microscope (magnification, x100) and demonstrated that S-100 (+), epithelial membrane antigen (EMA; -), glial fibrillary acidic protein (GFAP; -), Ki-67 (1\% +), epidermal growth factor receptor (-), cluster of differentiation (CD)34 (vascular +), CD31 (vascular + ) and vascular endothelial growth factor (-; Fig. 3). Follow-up of the patient was carried out 6 months after surgery and revealed that the recovery of the patient was good, binocular horizontal nystagmus was significantly relieved compared with that prior to the surgery, bilateral corneal reflexes were present, outreach activity barriers existed in the left eye, the patient had no cough when drinking water, speech was smooth and limb activity was free. The 5-year follow-up demonstrated no residual tumor or recurrence, whereas the neurological dysfunction of the patient was completely improved with no dysfunction (Fig. 4).

\section{Discussion}

Demographics and prevalence. Intracranial schwannoma accounts for between 5 and $8 \%$ of intracranial tumors, whereas intracerebral schwannoma, a rare disease, accounts for $<1 \%$ of intracranial schwannoma. A total of 84 cases previously reported within China and elsewhere were reviewed and summarized (Table I) (1-56). Gibson et al (5) reported a case of a 6-year-old male with a schwannoma in the temporal lobe that was surgically resected successfully for the first time in 1966. Erongun et al (33) summarized 35 cases (including the 1996 case), the youngest patient was 4 years old, whereas the oldest patient was 63 years old, with a median age of 21 years; the number of males and females was 18 and 17, respectively. Furthermore, brain schwannomas were predominantly identified in children and young people, including 26 patients $<30$ years old, accounting for $74.3 \%$ of total cases. Andrade et al (37) summarized and analyzed 55 cases reported in 2002, including 31 males and 24 females; the proportion of men was slightly higher at a male/female ratio of 1.29:1. Additionally, the median age was 21 years, and the age demonstrated a bimodal distribution, with 40 cases $<30$ years, accounting for $72.7 \%$ of total cases. The median age of the 36 cases with supratentorial tumors was 18 years, with a male/female ratio of $1.31: 1$, whereas the median age of patients with subtentorial tumors was 45 years, with a male/female ratio of 1.25:1. Patients with supratentorial intracerebral schwannomas were typically younger, whereas patients with subtentorial intracerebral schwannomas were older; however, no significant difference was identified between the incidence in men and women irrespective of supratentorial or subtentorial intracerebral schwannoma. A total of 84 cases reported within China and elsewhere were reviewed and analyzed, including 47 males and 37 females with a male/female ratio of 1.27:1. Furthermore, the youngest case was 6 months old, whereas the oldest case was 84 years old, with a median age of 23 years. Notably, the age demonstrated a bimodal distribution, including 55 cases $<30$ years, accounting for $65.5 \%$ of total cases. Additionally, the median age of the 61 cases with supratentorial intracerebral schwannomas was 21 years; however, the median age of patients with subtentorial intracerebral schwannomas was 48 years (Fig. 5). Therefore, this suggests that intracerebral schwannoma occurred at no specific age and demonstrated bimodality, with a peak at 20 years; however, the age of the majority of patients was $<30$ years. Furthermore, the proportion of males was higher compared with females, which is consistent with the characteristics of intracranial tumors. Additionally, the incidence of supratentorial intracerebral schwannoma was increased at a younger age (median of 21 years), whereas the incidence of subtentorial intracerebral schwannoma was increased at an older age (median of 48 years). However, the 

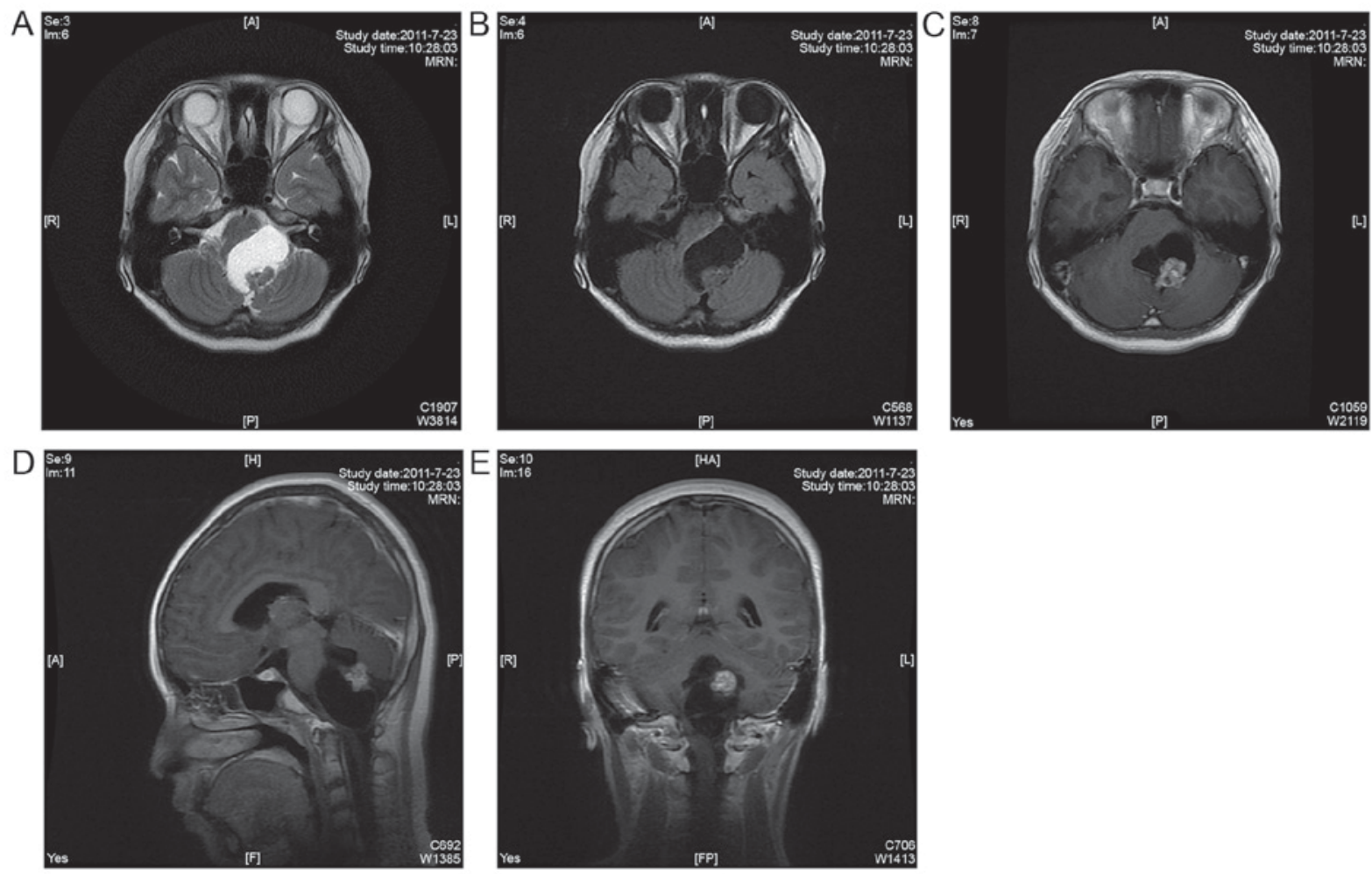

Figure 1. (A) MRI T2 sequence and (B) MRI T1 sequence demonstrated that a cystic abnormal signal was observed in the brainstem parenchyma, and parenchyma parts exhibited nodular isointensity shadows above the cystic wall. (C) MRI T1-weighted axial enhanced sequence, (D) MRI T1- weighted sagittal enhanced sequence, (E) MRI T1-weighted coronary enhanced sequence demonstrated that nodular lesions were mainly isointensity shadows, and the mass effect of the lesion was significant. Additionally, lesions were heterogeneously enhanced following injection of contrast material. A, anterior; P, posterior; R, right; L, left; H, head; F, feet; HA, head anterior; FP, foot posterior; MRN, magnetic resonance neurography

present case report describes a 12-year-old female who was diagnosed with a subtentorial schwannoma in the brainstem. To the best of our knowledge, this present case report is the second to diagnose the disease in a patient $\leq 12$ years of age.

Pathogenic site. The majority of intracerebral schwannomas are supratentorial, which typically occur in the superficial sections of the brain parenchyma or near the ventricle; however, previous studies have demonstrated that these are likely to occur in the frontal and temporal lobes of the cerebral hemisphere, as well as within the cerebellar hemisphere, cerebellar vermis and the fourth ventricle $(4,39)$. Erongun et al $(33)$ summarized that $27 / 35$ cases $(77.1 \%)$ with supratentorial intracerebral schwannomas occurred at a younger age with a distribution of 9 cases in the frontal lobe, 5 cases in the parietal lobe, 5 cases in the temporal lobe, 3 cases in the top occipital lobe, 1 case in the frontotemporal lobe and 1 case in the cerebral hemisphere. Andrade et al (37) demonstrated that $36 / 55$ cases $(65.45 \%)$ had supratentorial intracerebral schwannomas, including 13 cases in the frontal lobe, 12 cases in the temporal lobe, 9 cases in the parietal lobe, 1 case in the occipital lobe and 1 case in the cerebral hemisphere. Furthermore, of the 19 cases with subtentorial intracerebral schwannomas, 6 were located in the brainstem, and 13 were in the cerebellar hemisphere and vermis. In addition, Consales et al (50) provided further evidence for the distribution of intracerebral schwannoma and summarized 12 cases in 2010, including 3 cases in the frontal lobe, 4 cases in the temporal lobe, 1 case in the parietal lobe, 2 cases in the cerebellum, 1 case in the brainstem and 1 case in the hypothalamus. In total, 84 cases (Fig. 6) were summarized, including 61 cases of supratentorial intracerebral schwannomas $(72.6 \%)$, of which 24 were in the frontal lobe, 17 were in the temporal lobe, 12 were in the parietal lobe, 6 were in the occipital lobe and 2 were in the hypothalamus. Furthermore, 15 cases with subtentorial intracerebral schwannomas were in the cerebellar hemisphere and 8 cases were in the brainstem. Therefore, it can be concluded that intracerebral schwannomas are primarily supratentorial, typically located in the frontotemporal lobe, whereas subtentorial intracerebral schwannoma accounts for $<33 \%$ of the total intracerebral schwannomas, of which schwannomas within the brainstem exhibit an increased incidence. It is inferred that this part is close to the cranial nerves of the brainstem, which may be associated with the origin of intracerebral schwannoma.

Clinical manifestations. Intracerebral schwannoma has no specific clinical manifestation, and it is not classified by age. Its main clinical manifestations include epilepsy, increased intracranial pressure and local neurological dysfunction. Clinical manifestations in 84 patients were summarized and analyzed. The primary manifestations for patients $<25$ years old were headaches and epilepsy; however, elderly patients primarily suffered from acute local neurological dysfunction.

Imaging analysis. Results obtaining from imaging analysis demonstrated that characteristics of intracerebral schwannomas were similar to those of normal intracranial schwannomas. A typical imaging feature (57) of intracranial 

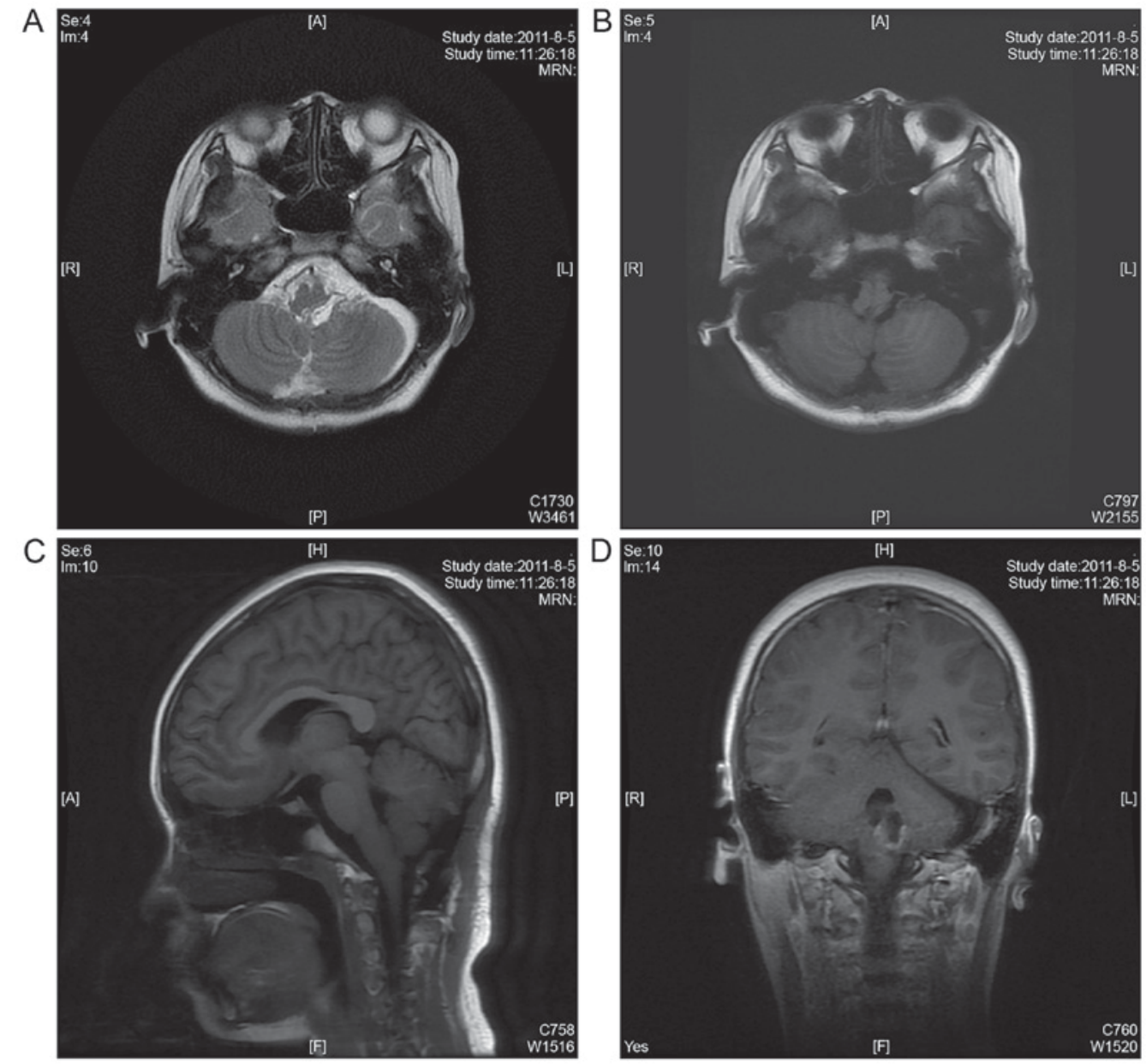

Figure 2. (A) MRI T2-weighted axial sequence, (B) MRI T1-weighted axial sequence, (C) MRI T1-weighted sagittal sequence, (D) MRI T1-weighted coronary sequence reviewed on the tenth day following surgery demonstrating that the tumor was completely resected, and the brainstem was back in the original position. MRI, magnetic resonance imaging. A, anterior; P, posterior; R, right; L, left; H, head; F, feet; MRN, magnetic resonance neurography.

A

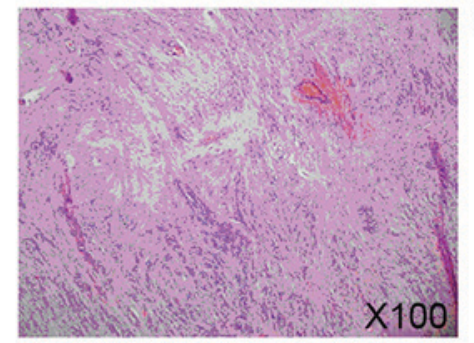

D

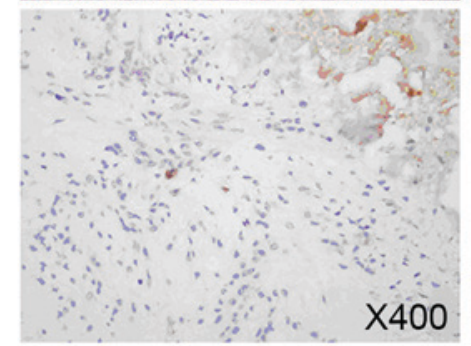

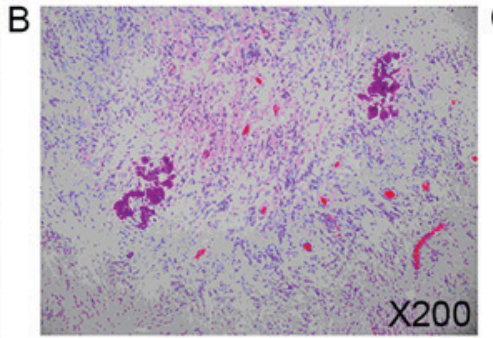

E

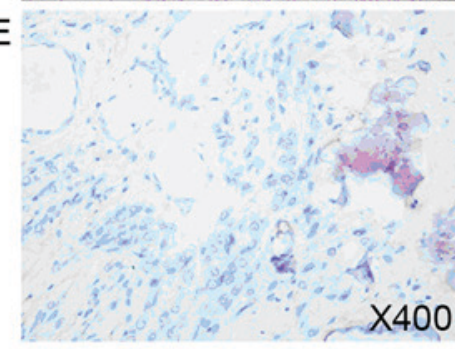

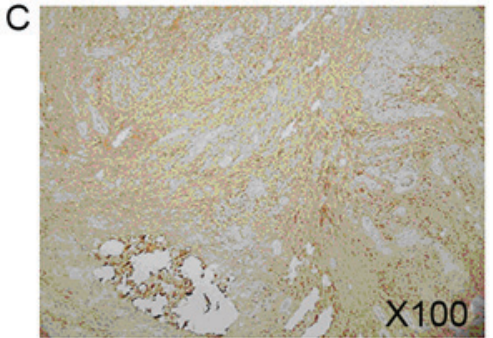

$\mathrm{X} 100$

Figure 3. (A) H\&E staining demonstrating the distribution of tumor cells was sparse with a fence-like arrangement (Antoni A-type structure; magnification, x100). (B) H\&E staining for tumor tissue combined with calcification (magnification, x200). (C) Positive S-100 staining the lower left side was combined with calcification (magnification, x100). (D) Epithelial membrane antigen protein staining was negative, the upper right side was combined with calcification (magnification, $\mathrm{x} 400$ ). (E) Glial fibrillary acidic protein was negative, the right side was combined with calcification (magnification, $\mathrm{x} 400$ ). H\&E, hematoxylin and eosin.

schwannomas was cystic masses with a clear boundary. Tumors were primarily located in the superficial part of the brain parenchyma, or the brain parenchyma near the ventricle with calcification. Additionally, edema was observed in the 
A

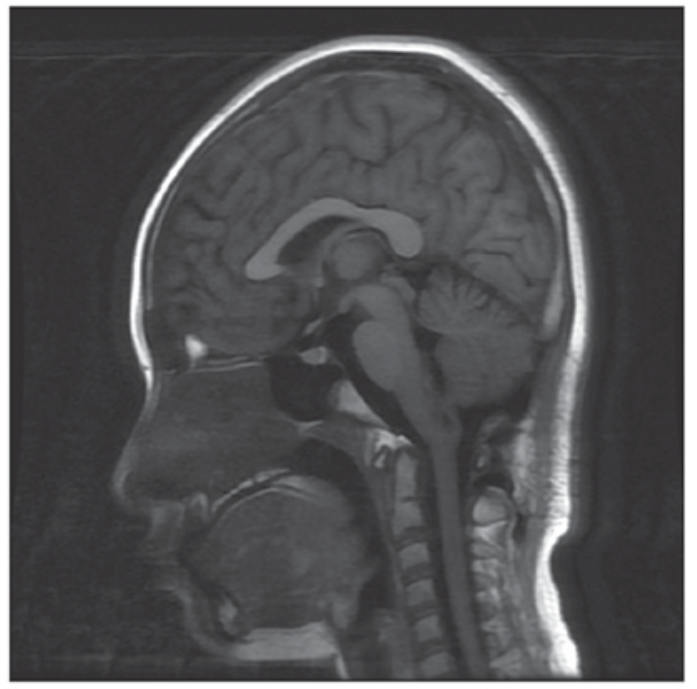

C

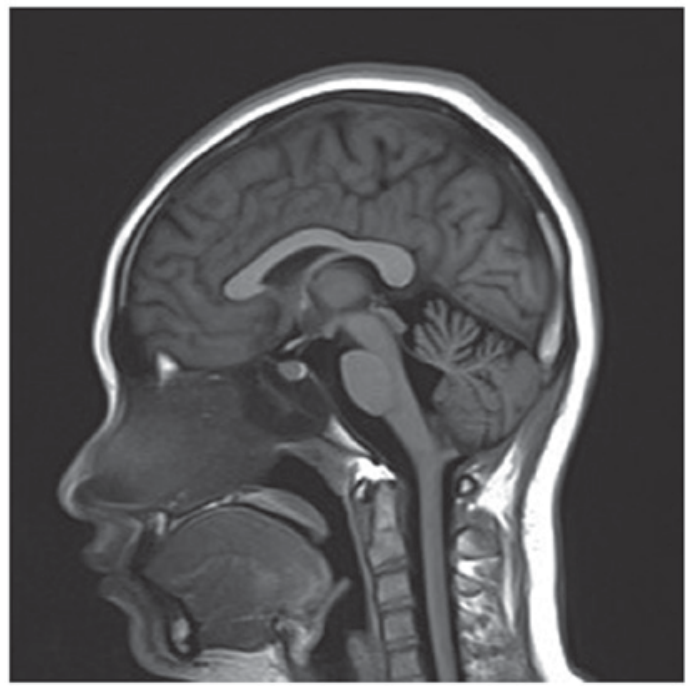

B

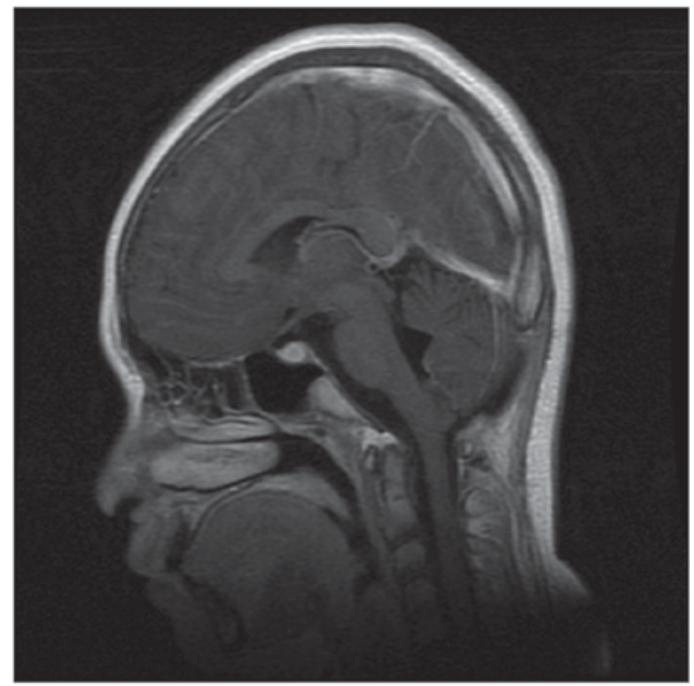

D

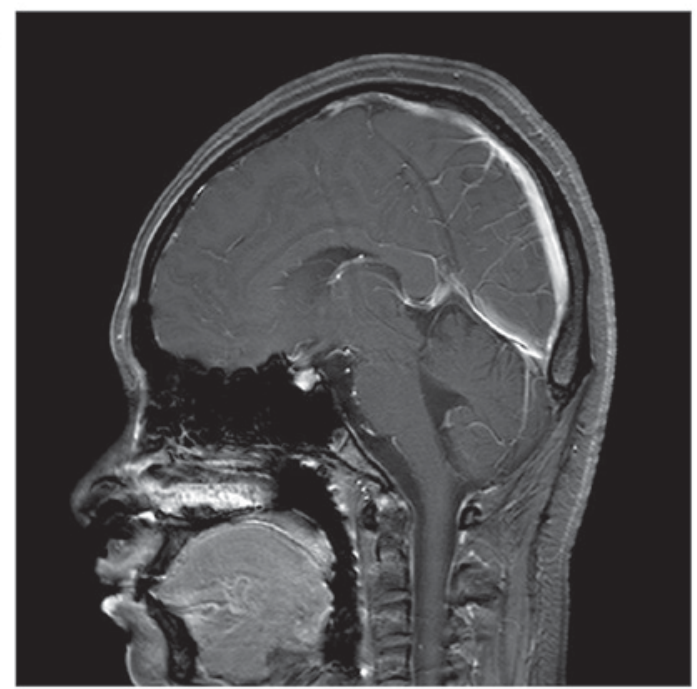

Figure 4. The magnetic resonance imaging of the 12 year old female was reviewed at (A) 3 months, (B) 1 year, (C) 3 years and (D) 4 years postoperatively, without recurrence of the tumor.

surrounding brain tissue, and the solid part of the tumor was homogeneously enhanced. However, not all intracranial schwannomas presented with cystic degeneration. It has been previously reported that $25.7 \%$ of tumors presented with cystic degeneration; however, calcification was rare (33). Results obtained from imaging analysis of the 12-year-old female included cystic mass lesions in the brainstem parenchyma, in which MRI T1 sequence and MRI T2 sequence mixed signal solid signal shadows were observed on the posterior capsule wall, and long T1 and short T2 signal shadows were observed in the tumor parenchyma. A combination of the aforementioned imaging results with high-density head computer tomography results demonstrated calcified shadow, deformation of the brainstem and cerebellar tissues around the tumor due to compression and mild edema. Parenchyma was strengthened following enhancement. Thus, no significant difference was reported between intracerebral schwannoma and ordinary schwannoma in MRI; however, there was a difference in the pathogenic site of origin (57).

Origin. The origin of the intracerebral nerve sheath remains unclear. It is well-documented that Schwann cells do not exist

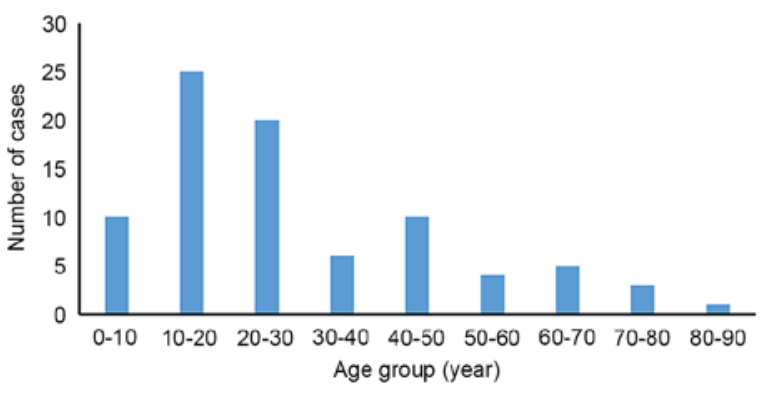

Figure 5. Age distribution for cases of subtentorial intracerebral schwannomas.

in the brain parenchyma; they are primarily in the choroidal tissues of the subarachnoid space, and the intracranial peripheral vascular plexus of the ventricle. Certain researchers believe that specific soft membrane cells have the potential to transform into Schwann cells, which are the origin of intracerebral schwannomas (58). Although the development of intracerebral schwannomas remains unclear, the majority of researchers claim that intracerebral schwannomas originate from the subarachnoid space and peripheral venous plexus (59). Nerve 
Table I. Data for 84 cases obtained from previous studies.

\begin{tabular}{|c|c|c|c|c|c|c|}
\hline Author(s) & Year of diagnosis & Age, years & Sex & Brain location & Site & (Refs.) \\
\hline Gibson et al, 1966 & 1966 & 6 & $\mathrm{M}$ & Supratentorial & Temporal & $(5)$ \\
\hline New, 1972 & 1972 & 8 & M & & Parietal & (6) \\
\hline Ghatak et al, 1975 & 1975 & 63 & $\mathrm{~F}$ & & Parietal & (7) \\
\hline Pialat et al, 1975 & 1975 & 24 & $\mathrm{~F}$ & & Frontal & $(8)$ \\
\hline Rensburg et al, 1975 & 1975 & 21 & $\mathrm{M}$ & & Temporal & (9) \\
\hline Hockley and Hendrick, 1975 & 1975 & 11 & M & & Temporal & $(10)$ \\
\hline Hahn and Netsky, 1977 & 1977 & 26 & M & & Frontal & (11) \\
\hline \multirow[t]{2}{*}{ Russel and Rubinstein, 1989} & 1977 & 17 & $\mathrm{M}$ & & Frontal & (1) \\
\hline & 1977 & 17 & $\mathrm{~F}$ & & Frontal & \\
\hline \multirow[t]{2}{*}{ Kasantikul et al, 1981} & 1981 & 21 & M & & Temporal & $(12)$ \\
\hline & 1981 & 23 & $\mathrm{M}$ & & Parietal & \\
\hline Auer et al, 1982 & 1982 & 15 & $\mathrm{M}$ & & Frontal & $(13)$ \\
\hline Shalit et al, 1982 & 1982 & 29 & $\mathrm{~F}$ & & Parieto-occipital & $(14)$ \\
\hline Gokay et al, 1984 & 1984 & 16 & $\mathrm{~F}$ & & Fronto-parietal & $(15)$ \\
\hline Rodriguez-Salazar et al, 1984 & 1984 & 10 & $\mathrm{~F}$ & & Frontal & $(23)$ \\
\hline Bruni et al, 1984 & 1984 & 39 & M & & Frontal & $(16)$ \\
\hline Bruner et al, 1984 & 1984 & 18 & M & & Frontal & $(24)$ \\
\hline Deng and $\mathrm{Wu}, 1985$ & 1985 & 53 & $\mathrm{~F}$ & & Parietal & $(25)$ \\
\hline Stefanko et al, 1986 & 1986 & 15 & M & & Parieto-occipital & $(17)$ \\
\hline Schwartz and Sotrel, 1988 & 1988 & 20 & $\mathrm{~F}$ & & Fronto-parietal & $(18)$ \\
\hline Ezura et al, 1992 & 1992 & 13 & $\mathrm{~F}$ & & Frontal & (19) \\
\hline Ghosh and Chandy, 1992 & 1992 & 27 & M & & Frontal & $(20)$ \\
\hline Frim et al, 1992 & 1992 & 11 & $\mathrm{~F}$ & & Temporal & $(21)$ \\
\hline \multirow[t]{6}{*}{ Casadei et al, 1993} & 1993 & 16 & M & & Temporal & (2) \\
\hline & 1993 & 17 & M & & Temporal & \\
\hline & 1993 & 21 & M & & Parietal & \\
\hline & 1993 & 23 & $\mathrm{~F}$ & & Temporal & \\
\hline & 1993 & 49 & $\mathrm{~F}$ & & Temporal & \\
\hline & 1993 & 84 & $\mathrm{~F}$ & & Temporal & \\
\hline Di Biasi et al, 1994 & 1994 & 19 & M & & Parietal & (3) \\
\hline Zhao et al, 1994 & 1994 & 38 & $\mathrm{M}$ & & Occipital & $(32)$ \\
\hline \multirow[t]{4}{*}{ Sharma et al, 1996} & 1996 & 19 & $\mathrm{~F}$ & & Occipital & (34) \\
\hline & 1996 & 8 & $\mathrm{M}$ & & Temporal & \\
\hline & 1996 & 0.5 & $\mathrm{~F}$ & & Temporal & \\
\hline & 1996 & 21 & $\mathrm{M}$ & & Frontal & \\
\hline Erongun et al, 1996 & 1996 & 4 & $\mathrm{~F}$ & & Parieto-occipital & $(33)$ \\
\hline \multirow[t]{2}{*}{ Tsuiki et al, 1997} & 1997 & 17 & $\mathrm{M}$ & & Frontal & $(35)$ \\
\hline & 1997 & 21 & $\mathrm{M}$ & & Frontal & \\
\hline \multirow[t]{4}{*}{ Wang et al, 2000} & 2000 & 45 & M & & Frontal & $(36)$ \\
\hline & 2000 & 34 & M & & Frontal & \\
\hline & 2000 & 12 & $\mathrm{~F}$ & & $\begin{array}{l}\text { Rear upper part of } \\
\text { the optic chiasm }\end{array}$ & \\
\hline & 2000 & 10 & M & & Parietal & \\
\hline Andrade et al, 2002 & 2002 & 17 & M & & Hypothalamus & $(37)$ \\
\hline Xu and Wang, 2002 & 2002 & 61 & $\mathrm{~F}$ & & Occipital & $(38)$ \\
\hline Zhong et al, 2004 & 2004 & 26 & M & & Frontal & $(40)$ \\
\hline Celikoglu et al, 2007 & 2007 & 23 & $\mathrm{~F}$ & & $\begin{array}{l}\text { Falx, right } \\
\text { parasagittal parietal }\end{array}$ & $(44)$ \\
\hline
\end{tabular}


Table I. Continued.

\begin{tabular}{|c|c|c|c|c|c|c|}
\hline Author(s) & Year of diagnosis & Age, years & Sex & Brain location & Site & (Refs.) \\
\hline \multirow[t]{3}{*}{ Xu et al, 2007} & 2007 & 31 & M & & Temporal & $(45)$ \\
\hline & 2007 & 17 & $\mathrm{~F}$ & & Frontal & \\
\hline & 2007 & 22 & $\mathrm{~F}$ & & Temporal & \\
\hline Yi et al, 2008 & 2008 & 43 & $\mathrm{~F}$ & & Frontal & (46) \\
\hline Ishihara et al, 2009 & 2009 & 5 & M & & Occipital & $(47)$ \\
\hline Zhu et al, 2010 & 2010 & 30 & M & & Frontal & (49) \\
\hline Consales et al, 2010 & 2010 & 7 & M & & Parieto-occipital & (50) \\
\hline \multirow[t]{2}{*}{ Paredes et al, 2012} & 2011 & 19 & M & & Occipital & (4) \\
\hline & 2011 & 32 & M & & Occipital & \\
\hline Guha et al, 2012 & 2012 & 51 & $\mathrm{~F}$ & & Temporal & $(51)$ \\
\hline Srinvias et al, 2013 & 2013 & 16 & $\mathrm{~F}$ & & Fronto-parietal & $(52)$ \\
\hline Lee et al, 2013 & 2013 & 25 & M & & Frontal & (53) \\
\hline Ma et al, 2013 & 2013 & 24 & $\mathrm{~F}$ & & Frontal & (54) \\
\hline AlBatly et al, 2014 & 2014 & 49 & $\mathrm{~F}$ & & Temporal & $(55)$ \\
\hline Wilson et al, 2016 & 2016 & 34 & M & & Temporal & $(56)$ \\
\hline Sarkar et al, 1987 & 1987 & 24 & M & Subtentorial & Cerebellum & $(22)$ \\
\hline Aryanpur and Long et al, 1988 & 1988 & 50 & $\mathrm{~F}$ & & Medulla oblongata & (26) \\
\hline Schwartz and Sotrel, 1988 & 1988 & 48 & M & & Cerebellum & (18) \\
\hline Ladouceur et al, 1989 & 1989 & 46 & $\mathrm{~F}$ & & Brainstem & $(27)$ \\
\hline Redekop et al, 1990 & 1990 & 7 & M & & Fourth ventricle & $(28)$ \\
\hline Tran-Dinh et al, 1991 & 1991 & 64 & $\mathrm{~F}$ & & Cerebellum & $(29)$ \\
\hline \multirow[t]{3}{*}{ Casadei et al, 1993} & 1993 & 52 & $\mathrm{~F}$ & & Cerebellum & (2) \\
\hline & 1993 & 55 & M & & Cerebellum & \\
\hline & 1993 & 79 & $\mathrm{~F}$ & & Cerebellar vermis & \\
\hline Sharma et al, 1993 & 1993 & 73 & M & & Cerebellum & $(30)$ \\
\hline Sharma and Newton, 1993 & 1993 & 73 & $\mathrm{~F}$ & & Cerebellum & $(31)$ \\
\hline \multirow[t]{4}{*}{ Sharma et al, 1996} & 1996 & 14 & M & & Brainstem & (34) \\
\hline & 1996 & 14 & M & & Pontine & \\
\hline & 1996 & 45 & M & & Cerebellum & \\
\hline & 1996 & 24 & M & & Cerebellum & \\
\hline Tsuiki et al, 1997 & 1997 & 64 & $\mathrm{~F}$ & & Cerebellum & (35) \\
\hline \multirow[t]{2}{*}{ Wang et al, 2000} & 2000 & 16 & $\mathrm{~F}$ & & Brainstem & (36) \\
\hline & 2000 & 49 & $\mathrm{~F}$ & & Cerebellum & \\
\hline Lin et al, 2003 & 2003 & 48 & $\mathrm{M}$ & & Medulla oblongata & (39) \\
\hline Maiuri et al, 2004 & 2004 & 29 & $\mathrm{~F}$ & & Cerebellar & $(42)$ \\
\hline Zeng et al, 2005 & 2005 & 15 & M & & Medulla oblongata & $(41)$ \\
\hline Muzzafar et al, 2010 & 2010 & 68 & M & & Brainstem & $(48)$ \\
\hline Present case report & 2016 & 12 & $\mathrm{~F}$ & & Medulla oblongata & \\
\hline
\end{tabular}

M, male; F, female.

fibers of the trigeminal nerve that dominate the dura mater are considered to be the origin of intracerebral schwannomas near to the dural convexity; however, certain intracerebral schwannomas are located deep in the brain parenchyma and peripheral vascular plexus of the cerebral arteries. This is because the majority of intracerebral schwannomas are located in superficial sections of the brain surface or near the ventricle adjacent to the brain surface. Therefore, Schwann cells in the peripheral venous plexus of the subarachnoid space may proliferate inward and further transform into intracerebral schwannomas $(60,61)$. Several previous studies have investigated molecular markers and confirmed that Schwann 


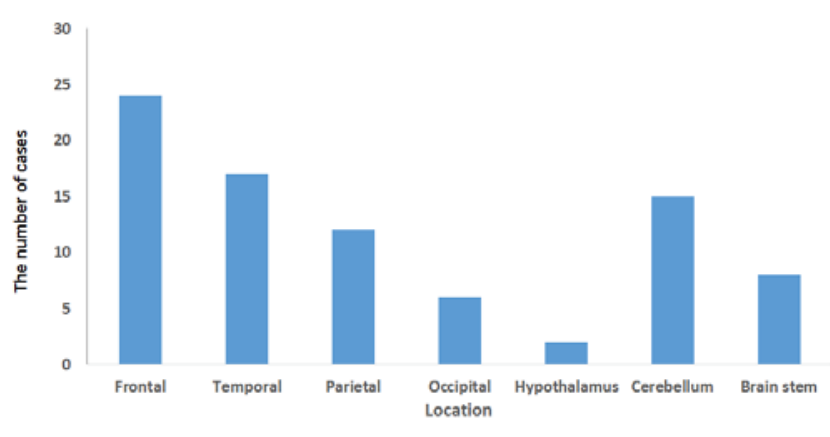

Figure 6. Intracerebral schwannoma location distribution.

cells originate from neural crest cells. SRY-related HMG-box 10 (SOX10) exists throughout the maturation process, activator protein $2 \alpha$ (AP2 $\alpha$ ) exists in the precursor stage prior to neural crests transforming into Schwann cells and cadherin-19 exists only in the precursor stage of Schwann cells. Brain fatty acid-binding protein and $\mathrm{P} 0$ markers exist in the precursor stage and later stages of Schwann cell maturation. GFAP and S-100 are expressed in the immature stage of Schwann cells but not in Schwann cell precursors. Early developmental markers including paired box (PAX) 3 and PAX7 are often associated with malignancy, whereas AP $2 \alpha$ and markers of late SOX10 are present in relatively benign tumors including schwannomas and gangliomas. Notably, PAX3 and PAX7 are present in the mesoderm, whereas AP2 $\alpha$ and SOX10 are expressed in the ectoderm. However, IHC staining of intracerebral schwannomas revealed S-100 (+), GFAP (-) and EMA (-). Neural crest cells directly differentiate into Schwann cell precursors that further transform into immature Schwann cells, which at the stage of fetal birth differentiate into medulla or demyelinated Schwann cells (60-63). Therefore, it has been suggested in previous studies that neural crest cells trapped in the brain at the stage of embryonic development are the cause of the occurrence of intracerebral schwannomas (64). Russel and Rubinstein (1) considered that mesenchymal cells with a soft membrane and Schwann cells exhibit tissue similarity, and the histological transformation may lead to schwannomas of the central nervous system.

Pathology. Intracranial schwannoma accounts for $\sim 8 \%$ of intracranial tumors and is not age-specific; however, previous results suggest a peak incidence at an age between 40 and 60 years, without sex orientation in the incidence rate. However, intracerebral schwannoma is a rare disease and accounts for $<1 \%$ of intracranial schwannomas. In addition, the number of males is greater compared with the number of females, which may be due to the fact that, overall, more male patients are diagnosed with intracranial tumors compared with females. Typical schwannomas have two types of tissue conformations: The dense Antoni A and the loose Antoni B (65). Histopathological analysis of the 12-year-old case revealed a staggered arrangement of sparse and dense areas of the Schwann cell, which was associated with local focal calcification. Tumor cells were oval with small nuclei; however, the mitotic figure was difficult to observe. IHC staining demonstrated that S-100 was expressed in tumor cells, negative expression of EMA and GFAP was able to distinguish meningiomas and gliomas, and the proliferation index of Ki-67 was not increased (1\% of positive expression) indicating that tumor cell proliferation was slow.

Prognosis. The prognosis for the majority of cases reviewed in the present case report was classified as being good; however, 3 cases $(23,33,42)$ demonstrated a markedly high level of malignancy (spread to other organs) and Rodriguez et al (23) reported 1 case of moderate malignancy (intracranial relapse), and, despite reoccurrence of the tumor, the prognosis was good following a second round of surgery. Bruner (24) reported a patient who succumbed 5 months after surgery due to postoperative secondary meningitis. Erongun et al (33) reported a 4-year-old female who presented with a tumor in the left parietal lobe and a high level of malignancy, as demonstrated using postoperative pathological analysis. Furthermore, the patient received surgery three times within an 8-month period and died from complications generated from having multiple surgeries 1 month after the last operation. The 5-year follow-up on the 12-year-old female revealed no reoccurrence of the tumor and also the neurological dysfunction of the patient had improved.

Conclusion. The incidence of intracerebral subtentorial schwannoma is low, with the majority of cases being supratentorial and primarily occurring at a young age. In total, $33 \%$ of patients exhibit subtentorial schwannoma, occurring predominantly at an older age; however, the 12-year-old female described in the present case report exhibited a very rare condition: Subtentorial schwannoma located in the brainstem. Usually, a correct diagnosis cannot be achieved prior to the operation because intracerebral schwannoma is a rare disease. Therefore, subtentorial schwannoma is typically diagnosed on the basis of postoperative pathological analysis. If the tumor can be completely removed, the prognosis of the patient is good.

\section{Acknowledgements}

Not applicable.

\section{Funding}

No funding was received.

\section{Availability of data and materials}

The datasets used and/or analyzed during the current study are available from the corresponding author on reasonable request.

\section{Authors' contributions}

XJ conceived and designed the study. YG, ZQ, DL, WY, LS and NL acquired the data, acquired and managed the patients and provided the radiology images. CZ, BZ, YH and DS contributed to the study design and analyzed and interpreted the data. XJ supervised the study.

\section{Ethics approval and consent to participate}

The present study was approved by the Ethics Committee of the China-Japan Union Hospital of Jilin University. The patient provided written informed consent for the present study. 


\section{Patient consent for publication}

The patient and his father consented to contribute his radiology images, hematology and pathological sections to medical research, for copyright and ethics without controversy.

\section{Competing interests}

The authors declare that they have no competing interests.

\section{References}

1. Russel DS and Rubinstein LJ: Pathology of tumors of the nervous system. Edward Arnold, London, 1989.1.

2. Casadei GP, Komori T, Scheithauer BW, Miller GM, Parisi JE and Kelly PJ: Intracranial parenchymal schwannoma. A clinicopathological and neuroimaging study of nine cases. J Neurosurg 79 217-222, 1993.

3. Di Biasi C, Trasimeni G, Iannilli M, Polettini E and Gualdi GF: Intracerebral schwannoma: CT and MR findings. AJNR Am J Neuroradiol 15: 1956-1958, 1994.

4. Paredes I, Jimenez Roldán L, Ramos A, Lobato RD and Ricoy JR: Intraparenchymal schwannomas: Report of two new cases studied with MRI and review of the literature. Clin Neurol Neurosurg 114: 42-46, 2012.

5. Gibson AA, Hendrick EB and Conen PE: Case reports. Intracerebral schwannoma. Report of a case. J Neurosurg 24 552-557, 1966.

6. New PF: Intracerebral schwannoma. Case report. J Neurosurg 36: 795-797, 1972.

7. Ghatak NR, Norwood CW and Davis CH: Intracerebral schwannoma. Surg Neurol 3: 45-47, 1975.

8. Pialat J, Sindou M, Courjon J, Tommasi M and Mansuy L: Un cas de neurinome intracerebral frontal. Lyon Med 234: 129-134, 1975 (In French).

9. Van Rensburg MJ, Proctor NS, Danziger J and Orelowitz MS: Temporal lobe epilepsy due to an intracerebral Schwannoma: Case report. J Neurol Neurosurg Psychiatry 38: 703-709, 1975.

10. Hockley AD and Hendrick EB: Unilateral proptosis and intracranial schwannoma. Surg Neurol 4: 509-512, 1975.

11. Hahn J and Netsky M: Brain tumors of mixed tissue origin: Staining procedures to distinguish glial from connective tissue. South Med J 70: 539-542, 1977.

12. Kasantikul V, Brown WJ and Cahan LD: Intracerebral neurilemmoma. J Neurol Neurosurg Psychiatry 44: 1110-1115, 1981.

13. Auer RN, Budny J, Drake CG and Ball MJ: Frontal lobe perivascular schwannoma. Case report. J Neurosurg 56: 154-157, 1982.

14. Shalit MN, Toledo E and Sandbank U: Intracerebral schwannoma. Acta Neurochir (Wein) 64: 253-258, 1982.

15. Gokay H, Izgi N, Barlas O and Erseven G: Supratentorial intracerebral schwannomas. Surg Neurol 22: 69-72, 1984.

16. Bruni P, Esposito S, Greco R and Oddi G: Solitary intracerebral schwannoma in von Recklinghausen's disease. Surg Neurol 22 360-364, 1984.

17. Stefanko SZ, Vuzevski VD, Maas AI and van Vroonhoven CC: Intracerebral malignant schwannoma. Acta Neuropathol 71: 321-325, 1986

18. Schwartz AM and Sotrel A: Intracerebral and intracerebellar neurilemoma. South Med J 81: 385-388, 1988.

19. Ezura M, Ikeda H, Ogawa A and Yoshimoto T: Intracerebral schwannoma: Case report. Neurosurgery 30: 97-100, 1992.

20. Ghosh S and Chandy MJ: Solitary ectopic intracerebral schwannoma. Br J Neurosurg 6: 163-166, 1992.

21. Frim DM, Ogilvy CS, Vonsattal JP and Chapman PH: Is intracerebral schwannoma a developmental tumor of children and young adults? Case report and review. Pediatr Neurosurg 18: 190-194, 1992

22. Sarkar C, Mehta VS and Roy S: Intracerebellar schwannoma. Case report. J Neurosurg 67: 120-123, 1987.

23. Rodriguez-Salazar A, Carrillo R and de Miguel J: Intracerebral schwannoma in a child: Report of a case. Childs Brain 11: 69-72, 1984.

24. Bruner JM, Hunphreys JH and Armstrong OL: Intracerebral nerve sheath tumor. J Neuropathol Exp Neurol 43: 296, 1984.

25. Deng C and Wu P: Intracranial ectopic neurilemoma: Report of two cases. J Nantong University 1: 46-47, 1985.
26. Aryanpur J and Long DM: Schwannoma of the medulla oblongata. Case report. J Neurosurg 69: 446-449, 1988.

27. Ladouceur D, Bergeron D, Lamarche JB and Lamontagne L: Cystic schwannoma of the brainstem. Can J Neurol Sci 16: 357-360, 1989.

28. Redekop G, Elisevich K and Gilbert J: Fourth ventricular schwannoma. Case report. J Neurosurg 73: 777-781, 1990.

29. Tran-Dinh HD, Soo YS, O'Neil P and Chaseling R: Cystic cerebellar schwannoma: Case report. Neurosurgery 29: 296-299; discussion 299-300, 1991.

30. Sharma RR, Gurusinghe NT, Lynch PG, Parekh HC and Bertolis G: Intraparenchymatous schwannoma of the cerebellum. Br J Neurosurg 7: 83-89, 1993.

31. Sharma V and Newton G: Schwannoma of the medulla oblongata. Br J Neurosurg 7: 427-429, 1993.

32. Zhao X, Wang Y and Duan M: Mixed brain cysticercosis with intracerebral schwannoma: A case study. Chin J Neurosurg 10: 280, 1994 (In Chinese).

33. Erongun U, Ozkal E, Acar O, Uygun A, Kocaoğullar Y and Gungor S: Intracerebral schwannoma: Case report and review. Neurosurg Rev 19: 269-274, 1996.

34. Sharma MC, Karak AK, Gaikwad SB, Mahapatra AK, Mehta VS and Sudha K: Intracranial intraparenchymal schwannomas: A series of eight cases. J Neurol Neurosurg Psychiatry 60: 200-203, 1996.

35. Tsuiki H, Kuratsu J, Ishimaru Y, Nakahara T, Kishida K, Takamura M, Marubayashi T and Ushio Y: Intracranial intraparenchymal schwannoma: Report of three cases. Acta Neurochir (Wein) 139: 756-760, 1997.

36. Wang H, Shi J, Tan Q and Sun K: Case report: Intracerebral schwannoma without the relationship of the brain nerve trunk. JiangSu Med J 26: 869-870, 2000 (In Chinese).

37. Andrade GC, Paiva Neto MA and Braga FM: Thalamic intracerebral schwannoma: Case report. Arq Neuropsiquiatr 60: 308-313, 2002 (In Portuguese).

38. Xu J and Wang Y: One case of intracerebral schwannoma. Chin J Neurosurg 18: 86, 2002 (In Chinese).

39. Lin J, Feng H, Li F, Zhao B and Guo Q: Intraparenchymal schwannoma of the medulla oblongata. Case report. J Neurosurg 98: 621-624, 2003

40. Zhong Q, Zhang X and Zhang Y: A case of schwannoma in brain parenchyma. Chin J Radiol 38: 1119-1120, 2004 (In Chinese).

41. Zeng E, Yuan X, Jiang W and Chen F: Brainstem schwannoma: One case report. Chin J Minima Invas Neurosur 10: 473, 2005.

42. Maiuri F, Colella G, D'Acunzi G and De Caro Mdel B: Malignant intracerebellar schwannoma. J Neurooncol 66: 191-195, 2004

43. Anton T, Guttierez J and Rock J: Tentorial schwannoma: A case report and review of the literature. J Neurooncol 76: 307-311, 2006.

44. Celikoğlu E, Hakan T and Bozbuğa M: Cystic schwannoma of the falx cerebri. J Clin Neurosci 14: 589-592, 2007.

45. Xu D, Chen D and Zhang Y: Magnetic resonance imaging of schwannoma in brain parenchyma (report of 3 cases). J Rare Uncom Dis 14: 7-10, 2007.

46. Yi Y, Zhou J and Lv S: A case of schwannoma in brain parenchyma. 19: 300-301, 2008.

47. Ishihara M, Miyagawa-Hayashino A, Nakashima Y, Haga H, Takahashi JA and Manabe T: Intracerebral schwannoma in a child with infiltration along perivascular spaces resembling meningioangiomatosis. Pathol Int 59: 583-587, 2009.

48. Muzzafar S, Ketonen L, Weinberg JS and Schellingerhout D: Imaging and clinical features of an intra-axial brain stem schwannoma. AJNR Am J Neuroradiol 31: 567-569, 2010.

49. Zhu Q, Jiang X and Ren Z: Schwannoma in brain parenchyma and literature review. Anhui Med J 31: 156-158, 2010 (In Chinese).

50. Consales A, Rossi A, Nozza P, Ravegnani M, Garrè ML and Cama A: Intracerebral schwannoma in a child. Br J Neurosurg 24: 306-308, 2010.

51. Guha D, Kiehl TR, Krings T and Valiante TA: Intracerebral schwannoma presenting as classic temporal lobe epilepsy. J Neurosurg 117: 136-140, 2012.

52. Srinivas R, Krupashankar D and Shasi V: Intracerebral schwannoma in a 16-year-old girl: A case report and review of the literature. Case Rep Neurol Med 2013: 171494, 2013.

53. Lee S, Park SH and Chung CK: Supratentorial intracerebral schwannoma: Its fate and proper management. J Korean Neurosurg Soc 54: 340-343, 2013.

54. Ma L, Yang SX and Wang YR: Intracerebral schwannoma mimicking parasagittal meningioma. J Craniofac Surg 24: e541-e543, 2013. 
55. AlBatly AA, Zakzouk RS and Alhaidey AK: An atypical case of intracerebral schwannoma. Pan Afr Med J 18: 342, 2014.

56. Wilson BR, Steinberg JA, Snyder V, Jiang MN and Carter BS Histologic evidence for arteriovenous malformation-like vasculature occurring within an intracerebral Schwannoma: A case report and review of the literature. World Neurosurg 92: 582 e589-582 e513, 2016.

57. Osborn AB and Salzman K: Diagnostic imaging: Brain Amirsys, Salt Lake City, 2007.

58. Feigin I and Ogata J: Schwann cells and peripheral myelin within human central nervous tissues: The mesenchymal character of Schwann cells. J Neuropathol Exp Neurol 30: 603-612, 1971.

59. Nelson E and Rennels M: Innervation of intracranial arteries. Brain 93: 475-490, 1970.

60. Scherer SS: The biology and pathobiology of Schwann cells. Curr Opin Neurol 10: 386-397, 1997.
61. Woodhoo A and Sommer L: Development of the Schwann cell lineage: From the neural crest to the myelinated nerve. Glia 56: 1481-1490, 2008

62. Mirsky R, Woodhoo A, Parkinson DB, Arthur-Farraj P, Bhaskaran A and Jessen KR: Novel signals controlling embryonic Schwann cell development, myelination and dedifferentiation. J Peripher Nerv Syst 13: 122-135, 2008.

63. Trotter J: The development of myelin-forming glia: Studies with primary cell cultures and immortalized cell lines. Perspect Dev Neurobiol 1: 149-154, 1993.

64. Chelyshev Iu A and Saitkulov KI: The development, phenotypic characteristics and communications of Schwann cells. Usp Fiziol Nauk 31: 54-69, 2000 (In Russian).

65. Li Q and Xu Z: Nervous system tumor pathology and genetics. People's Medical Publishing House Co., LTD. 